\title{
Comparison of Task Specific Exercises and Mirror Therapy to Improve Upper Limb Function in Subacute Stroke Patients
}

\author{
Sneha S. Khandare ${ }^{1}$, R. M. Singaravelan ${ }^{2}$, Subhash M. Khatri ${ }^{3}$ \\ I'Postgraduate student, College of Physiotherapy, PIMS, Loni- 413 736, India) \\ ${ }^{2}$ (Associate professor, College of Physiotherapy, PIMS, Loni- 413 736, India) \\ ${ }^{3}$ (Professor and Principal, College of Physiotherapy, PIMS, Loni- 413 736, India)
}

\begin{abstract}
Stroke is the leading cause of long-term disability. Approximately $70 \%$ to $80 \%$ of people sustaining a stroke have upper limb (UL) impairment. Improving use of the affected UL is important however, because difficulty in using this UL in daily tasks has been associated with reduced quality of life. Additional effects of combining mirror therapy (MT) with Task Specific Exercises (TSE) to improve UL function post-stroke are unknown. Hence, primary objective of this study was to find out the effectiveness of combined TSE and MT interventions in sub-acute stroke patients to improve UL function and secondary objective was to compare the effectiveness of combined TSE and MT interventions with TSE alone and MT alone. Thirty-seven stroke patients were divided into 3 groups; Group A received TSE, Group B received MT and Group C received TSE as well as MT. Outcome measures were Action Research Arm Test, Fugl-Meyer Assessment and Voluntary Control Grading. All 3 groups showed statistically significant improvement on outcome measures but Group C improved more than the other 2 groups. Conclusion: TSE and MT interventions should be combined altogether in the treatment of sub-acute stroke patients to improve UL function.
\end{abstract}

Keywords: Mirror therapy, Stroke, Task specific exercises, Task specific training, Upper limb function.

\section{Introduction}

Stroke is a major cause of disability in adults. One direct consequence of stroke is the loss of upper limb (UL) function. Whereas up to $83 \%$ of stroke survivors learn to walk again, it is estimated that only 5 to $20 \%$ of stroke survivors attain complete functional recovery of their affected UL [1,2]. Approximately $70 \%$ to $80 \%$ of people who sustain a stroke have upper-extremity impairment [3]. Many of them do not regain functional use of the paretic UL, which can lead to difficulties in activities of daily living (ADLs) and to participate in community life [4]. At 6 months post-stroke, a substantial proportion (25\%-53\%) of people remain dependent in at least 1 ADL task, which often involves the use of unilateral or bilateral UL movement [5]. Despite of these stark statistics, fortunately it is encouraging that, recent studies capitalizing on the concept of experience-induced neural-plasticity have produced promising results using specific interventions aimed at UL improving function [6]. One such intervention is task specific exercise.

Task-specific exercise (TSE) is defined as "a training or therapy where patient has to practice contextspecific motor tasks and receive some form of feedback [7]; with regard to skill learning, it may be associated with different practice conditions, feedback and conditions of transfer"[8,9]. TSE in rehabilitation focuses on improvement of performance in functional tasks through goal-directed practice and repetition. The focus is on training of functional tasks rather than impairments [10]. It has been recognized that 'movement emerges from an interaction between the individual, the task and the environment in which the task is being carried out' [11], this model is consistent with TSE. Other similar terms that reflect these practice elements are: 'task specific training' [10], 'repetitive functional task practice', 'repetitive task practice' [12], 'task-related training' [13] and 'task-orientated therapy' [14].

Isobel J. Hubbard et al. [10] has given five strategies to guide application of TSE in clinical practice which are consistent with the guidelines put forward by many other authors [15-20]. These guidelines can be formulated as five 'R's as: TSE should be relevant, repetitive, randomly ordered, aim towards reconstruction of whole task and positively reinforced [10]. There is increasing evidence of neural plastic changes associated with TSE [21]. These changes are associated with specific skill learning, consistent with a learning-dependent model of neural plasticity [22, 23]. Learning is reported to be maximal for the specific task trained [24].

Another relatively new intervention to improve UL function is mirror therapy (MT). Presenting visual feedback about motor performance to improve the effect of training is widespread in rehabilitation. A relatively new way of using this visual feedback to help the patients is exploited in MT [25]. Vilayanur Ramachandran, neurologist from United States first experimented MT in patients who suffered from a phantom limb after amputation [26]. During MT practice sessions, patient has to sit in front of a mirror that is oriented parallel to his midline blocking the view of the affected or painful limb which is positioned behind the mirror. When looking into the mirror, patient sees the reflection of unaffected limb positioned as the affected limb. This arrangement is suited 
to create a visual illusion whereby movement of or touch to the intact limb may be perceived as affecting the paretic or painful limb respectively. However, MT is still in its early stages, so there are no established protocols regarding its implementation [27]. Different studies have used different intervention characteristics.

There have been relatively many studies done where sub-acute stroke patients have been benefited either with TSE or with MT. Literature evidence also suggests that, the same cortical motor areas that are active during observation of movements; are also involved in the performance of the observed actions. In normal participants, the mirror illusion increases cortico-muscular excitability [22]. However, it is still not known whether this visual image produced by mirror illusion is more significant than the action itself to enhance the recovery of UL function. Also it is not still clear upto which extent the combination of TSE and MT is effective. Hence, this study was carried out to compare the TSE and MT interventions and also to find out the extent to which the combination of TSE and MT will improve UL function in subacute stroke patients.

\section{Methods}

2.1 Participants: This study was a prospective comparative study. Participants were recruited from the Neurophysiotherapy department, Pravara Institute of Medical Sciences, Loni (Bk) - 413 736, Taluka: Rahata, District: Ahmednagar, Maharashtra State, India. The study received approval from Institutional Ethical Committee (IEC) of Pravara Institute of Medical Sciences, Loni. Screening was done and 39 participants were randomly selected. They were explained about the nature of the study. One participant refused to participate. Written informed consents were obtained from the rest of 38 participants. Demographic data were noted. Outcome measures of the participants were recorded prior to intervention and also after completing 4 weeks of intervention. One participant dropped out from the study due to change of residential place. Drop-out rate was $2.56 \%$.

2.1.1 Inclusion criteria: The inclusion criteria for this study were as follows [28, 29, 30]

- Both male and female patients aged between 45 to 70 years

- Patients with first ever stroke

- Patients with having stroke from 2 months upto 1 year post-stroke

- Stroke with involvement of Middle Cerebral Artery on MRI or CT scan

- Patients with Voluntary Control Grading from 2 to 4 for affected UL

2.1.2 Exclusion criteria: Patients were excluded if they had [28, 29, 30]

- Poor cognitive function as assessed with Mini Mental State Examination score $<24$

- With uncontrolled systemic hypertension or

- With perceptual or apraxic deficits or

- Visual deficit such as homonymous hemianopia

- With reflex sympathetic dystrophy or

- With severe shoulder subluxation or

- Contracture in the affected UL

- Patients who have received botox injection or acupuncture within past 6 months to the affected UL

2.2 Outcome Measures: The outcome measures used for this study were:

- Action Research Arm Test (ARAT)

- Fugl-Meyer Assessment (FMA) of physical performance

- Voluntary Control Grading (VCG) Scale

2.3 Variables: The variables used in the study were -

- Dependent variables: Grasp, Grip, Pinch, Gross movement and Voluntary control

- Independent variables: Task specific exercises and Mirror therapy 


\subsection{Procedure:}

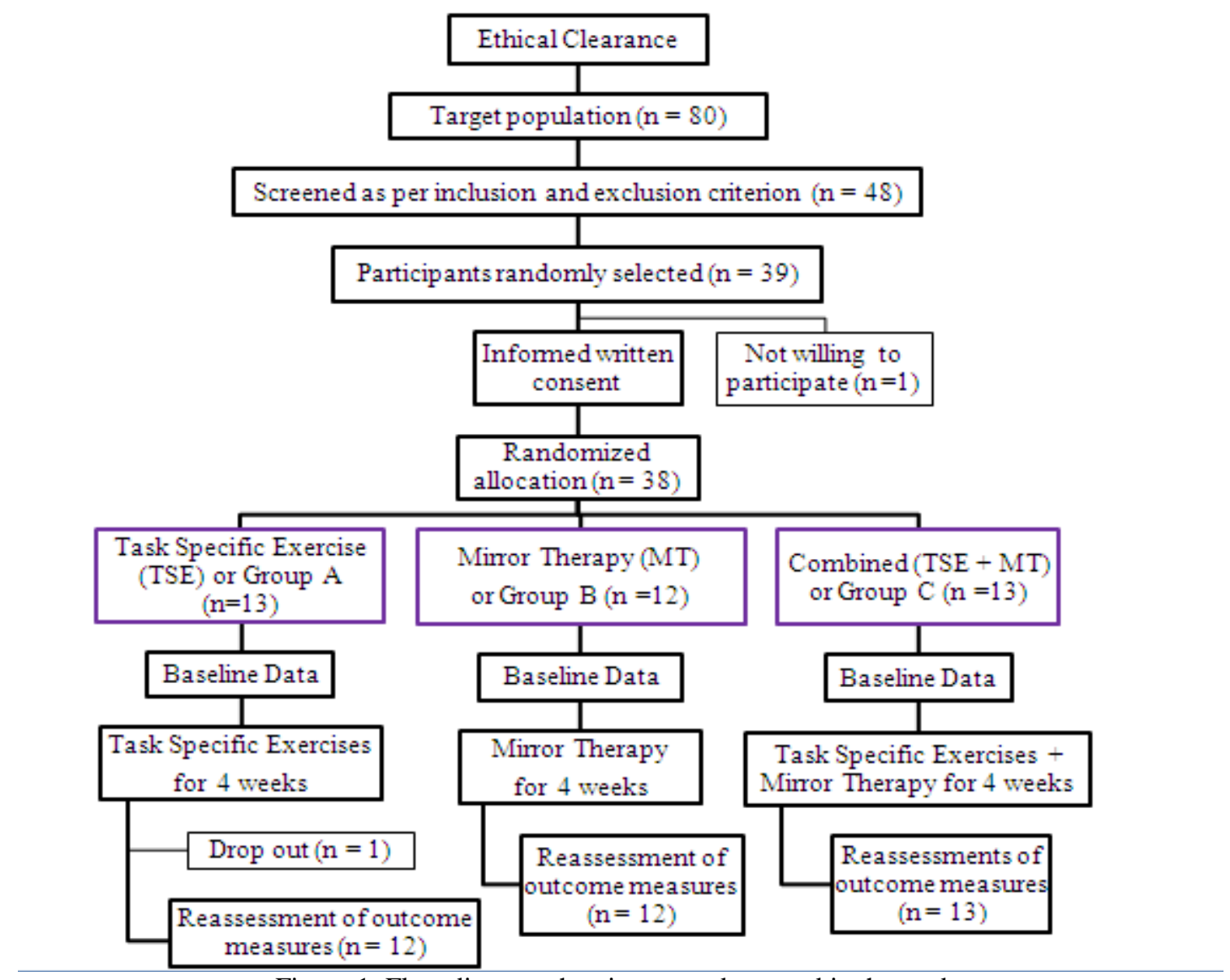

Figure 1: Flow diagram showing procedure used in the study

2.5 Intervention: Participants underwent randomized allocation into 3 groups using lottery method. All 3 groups received conventional physiotherapy and rest intervals were given whenever necessary. The three groups were as follows -

- Group A (TSE Group): had 12 individuals who received 30 minutes of task specific exercises

- Group B (MT Group): had 12 individuals who received 30 minutes of mirror therapy

- Group C (Combined Group): had 13 individuals who received 60 minutes of task specific exercises as well as mirror therapy.

\section{Group A: Task Specific Exercises Group (TSE Group):}

Patients in this group received Task Specific Exercises for 30 minutes per day for 5 days in a week for 4 weeks (total $=20$ sessions). This intervention focused on repetitive practice of meaningful tasks for patient by using affected upper limb [28]. It included following functional tasks: reaching, grasping, lifting, placing objects and counting with fingers [10,29].

Each of these tasks was performed for 5 repetitions. These tasks were performed with the participant seating and objects placed over the table of suitable height, provided participants had sufficient movement in their affected UL to attempt the functional tasks. For those participants who did not have sufficient movement in their affected UL to practice such tasks, therapist assisted the participant by guiding the limb through the tasks with the help of manual contact [31]. The difficulty level of practiced task was increased gradually, with the goal being set just above the patient's ability level to perform it [32]. Difficulty level was progressed by increasing the distance between participant and object and by decreasing the shape of the object. During treatment session, knowledge of results knowledge and knowledge of performance was provided as feedback [13]. Rest intervals were given whenever required for the total of 5 minutes in one treatment session. (Figure 2 and Figure 3) 


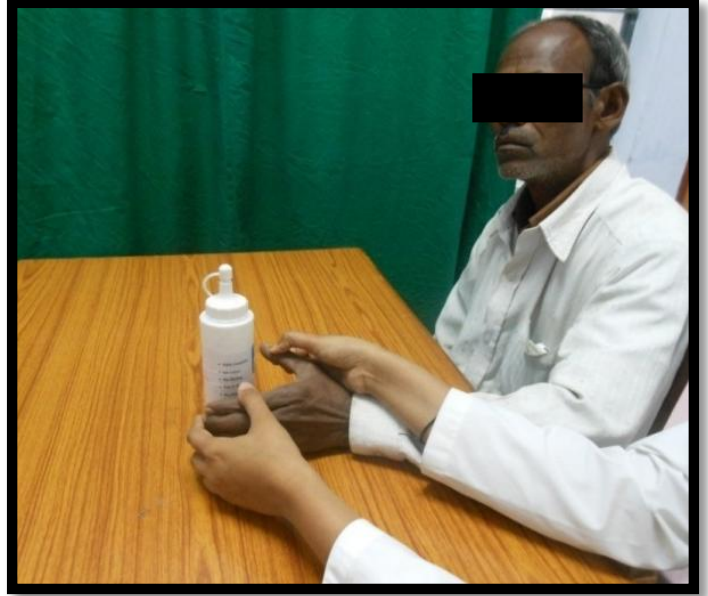

Figure 2: Grasping an object in TSE group

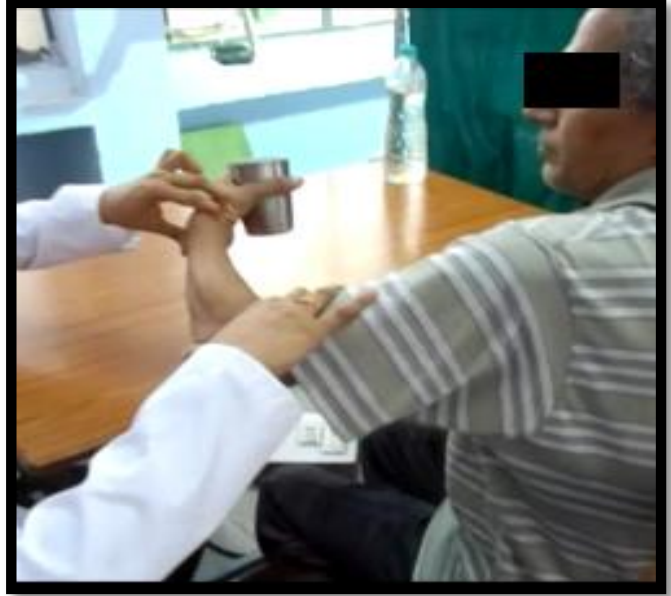

Figure 3: Lifting an object in TSE Group

\section{Group B: Mirror Therapy Group (MT Group):}

This group received mirror therapy program for 30 minutes per day for 5 days in a week for 4 weeks (total $=20$ sessions). Patients were seated close to a table on which a mirror (18 $\times 24$ inch) was placed vertically and in mid-sagital plane [30]. Affected UL was kept hidden behind the mirror and the unaffected UL was placed in front of the mirror. Patients in this group also practiced all above mentioned task specific activities with the same progression criteria but by using unaffected UL. This group also included following functional tasks: reaching, grasping, lifting, placing objects and counting with fingers.

Each of the above tasks was performed for 5 repetitions. They were instructed to watch the image of their unaffected upper UL in the mirror, thus seeing the reflection of unaffected UL movements projected over the affected UL. The imagery component was reinforced by then instructing the individual to "imagine that the reflected limb is in fact your limb moving about physically in space." [33] Rest intervals were given whenever required for the total of 5 minutes in one treatment session. (Figure 4 and Figure 5)

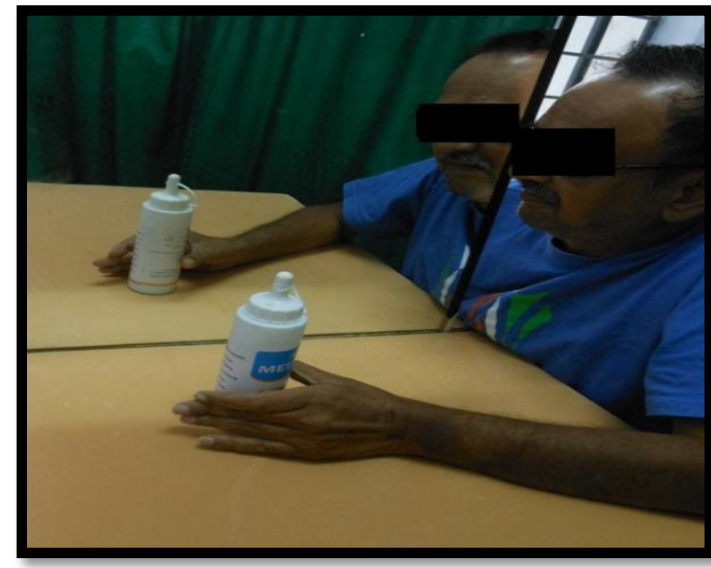

Figure 4: Grasping object in MT group

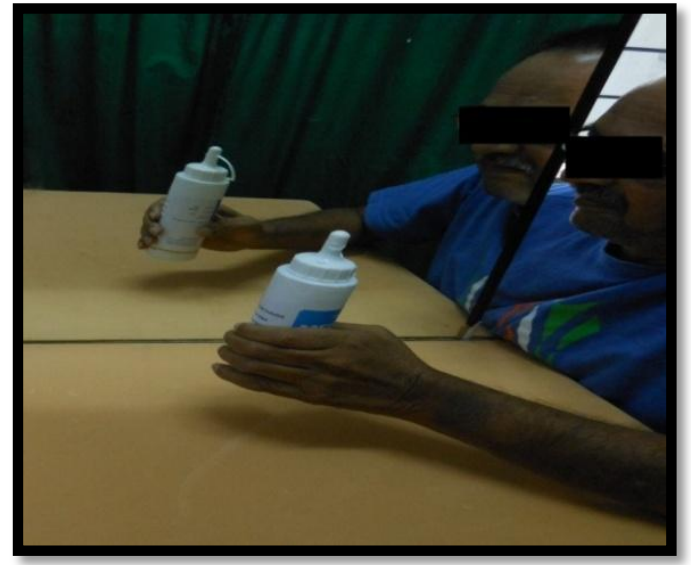

Figure 5: Lifting an object in MT group

\section{Group C: Combined Group:}

This group received both interventions for 60 minutes per day for 5 days in a week for 4 weeks (total $=$ 20 sessions) including 10 minutes of rest interval. TES were practiced for initial 30 minutes, in which participants practiced all the above mentioned tasks with the affected UL for initial 30 minutes including 5 minutes rest interval. Thereafter MT was practiced in which participants practiced same tasks with the unaffected UL for later 30 minutes. Rest intervals were given whenever required for the total of 5 minutes.

\section{Data Analysis And Results}

Data were analyzed using GraphPad Instat software - Trial version 3.10. Demographic variables and pre-intervention outcome measures between the groups were evaluated. The data was entered into an excel spread sheet, tabulated and subjected to statistical analysis. Various statistical measures such as mean, median, 
standard deviation (SD) and test of significance were utilized to analyze the data. Wilcoxon Matched Pair Test was used to compare the differences in scores between pre-intervention and post-intervention readings within a single group. Kruskal-Wallis Test was used to examine whether improvements from pre- to post-intervention were significantly different between the three intervention groups. The results were concluded to be statistically significant with $\mathrm{p}<0.05$ and highly significant with $\mathrm{p}<0.01$. When a significant difference was found between the three groups, a post-hoc Dunn's Multiple Comparison Test was applied to reveal which groups differ significantly from each other.

\subsection{Demographic Details and Baseline Measurements:}

No statistically significant differences were found at baseline between the three groups in terms of outcome measures. All demographic details are listed in Table 1 as follows.

Table 1: Demographic details and baseline measurements of patients in 3 groups

\begin{tabular}{|l|l|l|l|l|}
\hline & Group A & Group B & Group C & $\begin{array}{l}\text { 'p' } \\
\text { value* }^{*}\end{array}$ \\
\hline Age (years) & $56.75 \pm 6.85$ & $55.83 \pm 5.11$ & $57.69 \pm 4.55$ & $0.70^{\mathrm{a}}$ \\
\hline Gender (Male/ Female) & $\begin{array}{l}9(75 \%) / \\
3(25 \%)\end{array}$ & $\begin{array}{l}8(66.67 \%) / \\
4(33.34 \%)\end{array}$ & $\begin{array}{l}9(69.23 \%) / \\
4(30.77 \%)\end{array}$ & - \\
\hline $\begin{array}{l}\text { Post-stroke Duration } \\
\text { (days) }\end{array}$ & $187 \pm 83.96$ & $\begin{array}{l}189.25 \pm \\
89.80\end{array}$ & $\begin{array}{l}202.54 \pm \\
83.23\end{array}$ & $0.89^{\mathrm{a}}$ \\
\hline Dominant Side (Rt./Lt.) & $12(100 \%) /$ & $\begin{array}{l}11(91.67 \%) / \\
1(8.34 \%)\end{array}$ & $\begin{array}{l}12(92.30 \%) \\
1(7.69 \%)\end{array}$ & - \\
\hline Side of Weakness (Rt./Lt.) & $\begin{array}{l}7(58.33 \%) / \\
5(41.67 \%)\end{array}$ & $\begin{array}{l}8(66.67 \%) / \\
4(33.34 \%)\end{array}$ & $\begin{array}{l}8(61.54 \%) / \\
5(38.46 \%)\end{array}$ & - \\
\hline $\begin{array}{l}\text { Type of Lesion } \\
\text { (Infarction/ Haemorrhage) }\end{array}$ & $10(83.34 \%)$ & $\begin{array}{l}11(91.67 \%) \\
/ 1(8.34 \%)\end{array}$ & $\begin{array}{l}11(84.62 \%) / \\
2(15.38 \%)\end{array}$ & - \\
\hline ARAT & $21 \pm 12.87$ & $22.42 \pm 12.89$ & $21.69 \pm 11.66$ & $0.96^{\mathrm{b}}$ \\
\hline FMA & $24.25 \pm 11.18$ & $26.75 \pm 12.14$ & $27 \pm 11.90$ & $0.85^{\mathrm{b}}$ \\
\hline VCG & $2.75 \pm 0.75$ & $2.92 \pm 0.79$ & $2.69 \pm 0.75$ & $0.75^{\mathrm{b}}$ \\
\hline
\end{tabular}

Where:

* p value at baseline

${ }^{a}$ Analyzed by One way Analysis Of Variance (ANOVA)

${ }^{\mathrm{b}}$ Analyzed by Kruskal-Wallis one way analysis of variance by ranks test

\subsection{Intra-group comparisons:}

Table 2: Intra group comparison of outcome measures in group A

\begin{tabular}{|l|l|l|l|l|l|}
\hline $\begin{array}{l}\text { Outcome } \\
\text { Measure }\end{array}$ & $\begin{array}{c}\text { Antervention } \\
\text { scores } \\
\text { Mean } \pm \text { S.D. }\end{array}$ & $\begin{array}{l}\text { Post- } \\
\text { intervention } \\
\text { scores (4 weeks) } \\
\text { Mean } \pm \text { S.D. }\end{array}$ & $\begin{array}{l}\text { Mean change } \\
\text { (post-pre) } \\
\text { scores } \\
\text { Mean } \pm \text { S.D. }\end{array}$ & 'p' value & Result \\
\hline ARAT & $21 \pm 12.87$ & $25.5 \pm 12.82$ & $4.5 \pm 3.06$ & $<0.01$ & Highly significant \\
\hline FMA & $24.25 \pm 12.18$ & $29.58 \pm 12.02$ & $5.41 \pm 2.61$ & $<0.01$ & Highly significant \\
\hline VCG & $2.75 \pm 0.75$ & $3.34 \pm 0.89$ & $0.58 \pm 0.51$ & $<0.05$ & Significant \\
\hline
\end{tabular}

Table 3: Intra group comparison of outcome measures in group B

\begin{tabular}{|l|l|l|l|l|l|}
\hline $\begin{array}{l}\text { Outcome } \\
\text { Measure }\end{array}$ & $\begin{array}{c}\text { Pre- } \\
\text { intervention } \\
\text { scores } \\
\text { Mean } \pm \text { S.D. }\end{array}$ & $\begin{array}{l}\text { Post- } \\
\text { intervention } \\
\text { scores } \\
\text { weeks }) \\
\text { Mean } \pm \text { S.D. }\end{array}$ & $\begin{array}{l}\text { Mean change } \\
\text { (post-pre }) \\
\text { scores } \\
\text { Mean } \pm \text { S.D. }\end{array}$ & $\begin{array}{l}\text { 'p' } \\
\text { value }\end{array}$ & Result \\
\hline ARAT & $22.42 \pm 12.89$ & $24.66 \pm 13.90$ & $2.25 \pm 1.60$ & $<0.01$ & $\begin{array}{l}\text { Highly } \\
\text { significant }\end{array}$ \\
\hline FMA & $26.75 \pm 12.14$ & $30.25 \pm 11.67$ & $3.5 \pm 1.73$ & $<0.01$ & $\begin{array}{l}\text { Highly } \\
\text { Significant }\end{array}$ \\
\hline VCG & $2.92 \pm 0.79$ & $3.25 \pm 0.75$ & $0.34 \pm 0.49$ & $=0.12$ & Not Significant \\
\hline
\end{tabular}


Table 4: Intra group comparison of all outcome measures in group C

\begin{tabular}{|l|c|l|l|l|l|}
\hline $\begin{array}{l}\text { Outcome } \\
\text { Measure }\end{array}$ & $\begin{array}{c}\text { Pre- } \\
\text { intervention } \\
\text { scores } \\
\text { Mean } \pm \text { S.D. }\end{array}$ & $\begin{array}{l}\text { Post- } \\
\text { intervention } \\
\text { scores } 4 \\
\text { weeks) } \\
\text { Mean } \pm \text { S.D. }\end{array}$ & $\begin{array}{l}\text { Mean change } \\
\text { (post-pre) } \\
\text { scores } \\
\text { Mean } \pm \text { S.D. }\end{array}$ & $\begin{array}{l}\text { 'p' } \\
\text { value }\end{array}$ & Result \\
\hline ARAT & $21.69 \pm 11.66$ & $28.77 \pm 11.90$ & $7.23 \pm 1.79$ & $<0.01$ & $\begin{array}{l}\text { Highly } \\
\text { significant }\end{array}$ \\
\hline FMA & $27 \pm 11.90$ & $35.38 \pm 11.44$ & $8.38 \pm 2.14$ & $<0.01$ & $\begin{array}{l}\text { Highly } \\
\text { Significant }\end{array}$ \\
\hline VCG & $2.69 \pm 0.75$ & $3.85 \pm 0.90$ & $1.15 \pm 0.69$ & $<0.01$ & $\begin{array}{l}\text { Highly } \\
\text { Significant }\end{array}$ \\
\hline
\end{tabular}

\subsection{Inter-group Comparison:}

Table 5: Inter-group comparison of 3 groups in terms of outcome measures

\begin{tabular}{|c|c|c|c|c|l|}
\hline $\begin{array}{c}\text { Outcome } \\
\text { Measure }\end{array}$ & $\begin{array}{c}\text { Group A } \\
\text { Mean } \pm \text { S.D. }\end{array}$ & $\begin{array}{c}\text { Group B } \\
\text { Mean } \pm \text { S.D. }\end{array}$ & $\begin{array}{c}\text { Group C } \\
\text { Mean } \pm \text { S.D. }\end{array}$ & $\begin{array}{c}\text { 'p' } \\
\text { value }\end{array}$ & Result \\
\hline ARAT & $4.5 \pm 3.06$ & $2.25 \pm 1.60$ & $7.23 \pm 1.79$ & 0.0001 & $\begin{array}{l}\text { Highly } \\
\text { significant }\end{array}$ \\
\hline FMA & $5.42 \pm 2.61$ & $3.5 \pm 1.73$ & $8.38 \pm 2.14$ & 0.0001 & $\begin{array}{l}\text { Highly } \\
\text { Significant }\end{array}$ \\
\hline VCG & $0.58 \pm 0.51$ & $0.33 \pm 0.49$ & $1.15 \pm 0.69$ & 0.0087 & $\begin{array}{l}\text { Highly } \\
\text { Significant }\end{array}$ \\
\hline
\end{tabular}

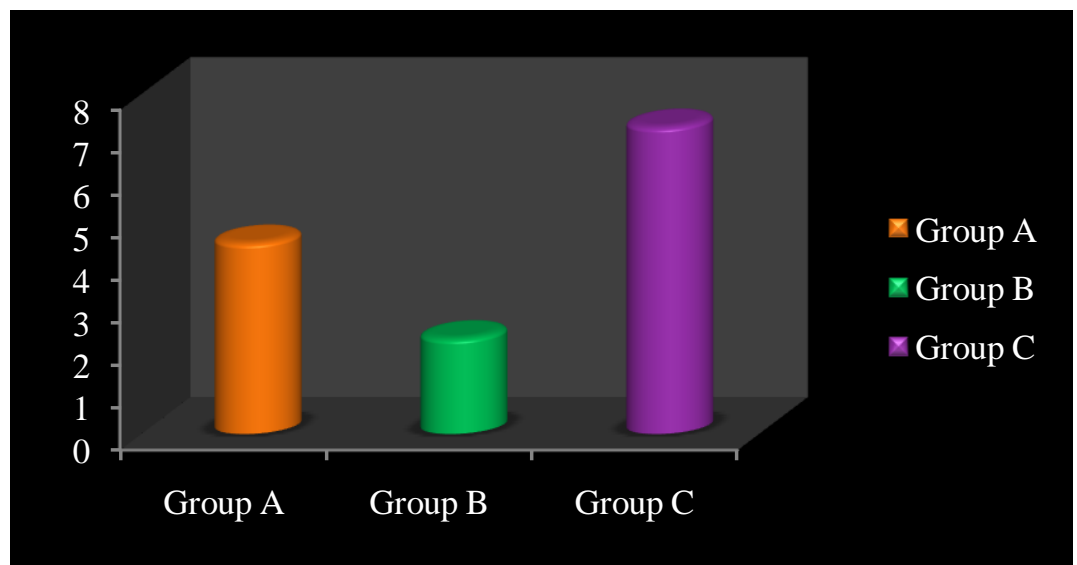

Graph 1: Intergroup comparison of ARAT Mean difference scores

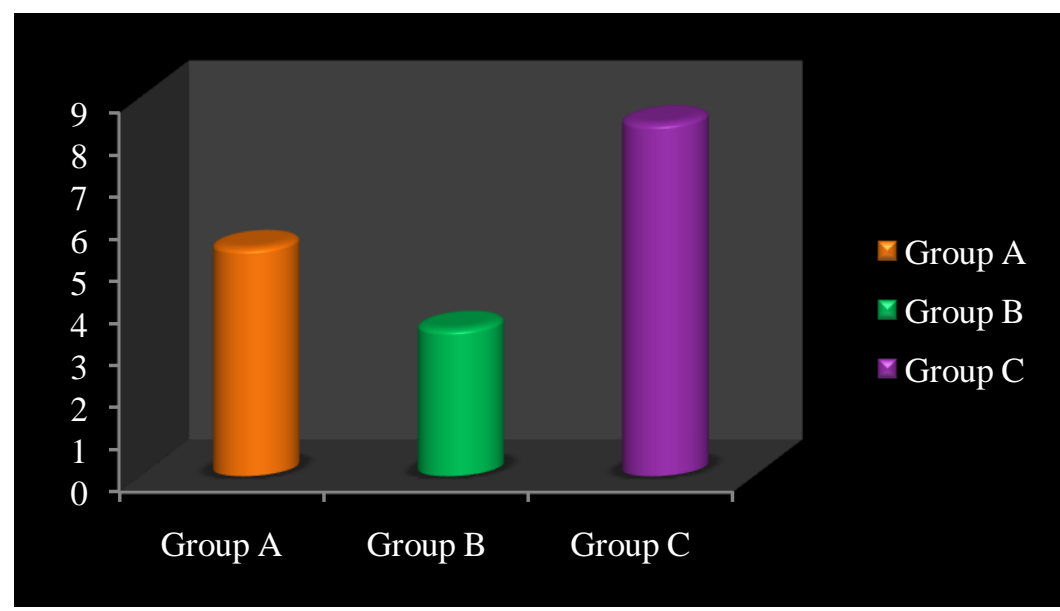

Graph 2: Intergroup comparison of FMA Mean difference scores 


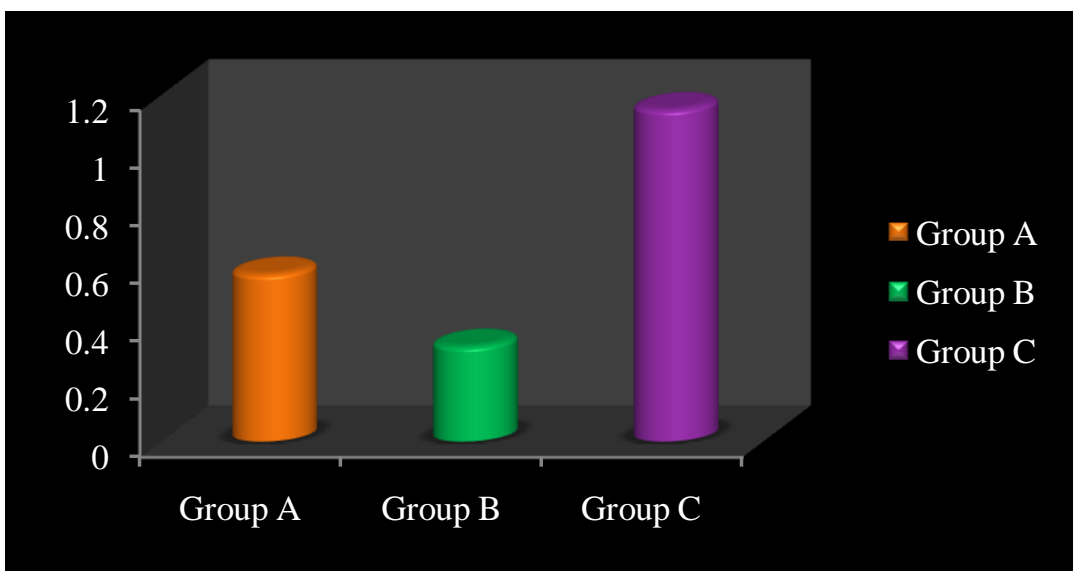

Graph 3: Intergroup comparison of VCG Mean difference scores

\section{Discussion}

The aim of this study was to find out the combined effectiveness of task specific exercises along with mirror therapy as compared with task specific exercises alone and mirror therapy alone to improve upper limb function in sub-acute stroke patients. Total 37 Patients were included in this study, in that 12 patients were in group A (TSE group), 12 patients were in group B (MT group) and 13 patients were in group C (Combined group). The results of the present study indicates that all 3 groups showed improvement in UL function in terms of ARAT and FMA scores whereas improvement in VCG score was observed only in group A and group C. Overall improvement in the group $\mathrm{C}$ who received combined intervention of TSE and MT was greater than group A, which in turn was greater than group B.

\subsection{Task Specific Exercise Group (TSE Group or Group A):}

Patients in Group A received Task specific exercises (TSE) along with conventional physiotherapy. The mean difference in pre- and post-intervention ARAT scores was $4.5 \pm 3.06$ ( $\mathrm{p}<0.01$ ). There was $7.89 \%$ improvement in terms of ARAT. The mean difference in pre- and post-intervention FMA scores was $5.42 \pm 2.61$ $(\mathrm{p}<0.01)$. There was $8.08 \%$ improvement in terms of FMA scores. The mean difference in pre- and postintervention VCG scores was $0.58 \pm 0.15$ ( $\mathrm{p}<0.05$ ). There was $9.83 \%$ improvement in terms of VCG scores. These results show that there is statistically significant improvement in all outcome measures seen in Group A on intra-group comparison.

These results could be due to improved motor control, functional recovery and increased strength of UL [29]. TSE has also been linked to improve cortical reorganization. Animal studies have demonstrated that task-specific training can restore function by using non-affected parts of the brain which are generally adjacent to the lesion [34] and/or recruiting supplementary areas of the brain [23]. Neural plastic changes have also been demonstrated in the human brain following stroke and task specific intervention [21, 35, 36]. Jang SH et. al. [37] also noted decrease in the unaffected and an increase in the affected primary sensorimotor cortex activities along with functional recovery in stroke patients who received TSE. Classen et al. [38] using focal transcranial magnetic stimulation (TMS) has shown that TSE, in comparison to traditional stroke rehabilitation, yields longlasting cortical reorganization specific to the corresponding areas being used. Both Karni et al.[22] using functional magnetic resonance imaging (fMRI) and Classen et al.[38] using TMS reported a slowly evolving, long-term, experience-dependent reorganization of the adult primary motor cortex after daily practice of taskspecific motor activities.

Patients in this group practiced repeated meaningful tasks by affected UL. Most researchers [12, 29] recommend that the more the task is practiced, the better the overall performance. According to Kilgard and Merzenich [39] repetition plays a major role in inducing and maintaining brain changes. However, Page [40] suggested that intensity alone does not account for the differences between traditional stroke and task-specific rehabilitation. Task-specific sessions, consisting of thumb and hand movements, for as short as 15 minutes have resulted in lasting cortical representational changes [38, 41]. Also research has demonstrated that rehabilitation may be more successful if the tasks and stimuli are important and meaningful to the person [14, 15].

Similar results were found by Winstein et al. [42] who reported that a significant difference in UL motor function was found for those with less severe stroke in favor of TSE versus standard care. Dean and Shepherd [43] also reported that after training, patients in the experimental group were able to reach faster and further. In comparison, improvements in reaching were not found with the control group. 


\subsection{Mirror Therapy Group (MT Group or Group B):}

Patients in Group B received mirror therapy (MT) along with conventional physiotherapy. The mean difference in pre- and post-intervention ARAT scores was $2.25 \pm 1.60(\mathrm{p}<0.01)$. There was 3.93\% improvement in terms of ARAT. The mean difference in pre- and post-intervention FMA scores was $3.5 \pm 1.73$ $(\mathrm{p}<0.01)$. There was 5.30\% improvement in terms of FMA. The mean difference in pre- and post-intervention VCG scores was $0.33 \pm 0.49(\mathrm{p}=0.125)$. There was $5.5 \%$ improvement in terms of VCG. This result shows that except VCG, there was statistically significant improvement in ARAT and FMA outcome measures in Group B on intra-group comparison. The result of this group shows that MT in addition to a conventional physiotherapy is beneficial in terms of improving UL function.

The neural mechanisms underlying the efficacy of MT are not clear. But several mechanisms have been proposed for the effect of MT on motor recovery after stroke. Ramachandran [44] originally hypothesized that paralysis following stroke might have a 'learned' component, which could possibly be 'unlearned' by means of the mirror illusion [45]. Within stroke patients, the sensomotoric coupling is often disturbed, which might compromise task-intrinsic feedback [27]. Therefore, to recover motor function stroke patients may be more dependent on augmented feedback [46]. This augmented feedback might be delivered in the form of visual feedback through MT [47]. In line with this notion, Stevens and Stoykov [33] have suggested that in MT, the mirror creates visual feedback of successful performance of the imagined action of the impaired limb.

Another possible working mechanism behind MT is the activation of mirror neuron system triggered by the observation of mirror illusion [48-50]. Mirror neurons discharge not only during action execution but also during action observation $[48,50]$. The discharge of these neurons is associated with object-oriented hand actions such as grasping, holding, tearing, and manipulating [51, 52]. Such neurons are found in the frontal lobes as well as in the parietal lobes [51]. These areas are rich in motor command neurons each of which fires to orchestrate a sequence of muscle twitches to produce simple skilled movements [44]. These cortical areas are supposed to be activated by MT which suggests that they might be involved in the efficacy of MT in stroke $[52,53]$.

The effect of mirror visual illusions on brain activity has also been investigated. Garry et al. [54] performed TMS during mirror illusions in healthy subjects and found increased excitability of primary motor cortex (M1) of the hand behind the mirror. However Michielsen et al. [55] reported that mirror illusion caused increased activity in the precuneus and the posterior cingulate cortex, these areas are associated with awareness of the self and spatial attention. The authors concluded that, by increasing awareness of the affected limb, the mirror illusion might reduce learnt non-use.

Results similar to the present study were reported by Gunes Yavuzer et al [56]. They found that hand function improved more after MT in addition to a conventional rehabilitation program as compared with a control treatment immediately after 4 weeks of treatment and at 6-month follow-up.

\subsection{Combined Group (Group C):}

Patients in Group C received combined intervention of task specific exercises and mirror therapy along with conventional physiotherapy. The mean difference in pre- and post-intervention ARAT scores was 7.23 \pm $1.79(\mathrm{p}<0.01)$. The percentage-wise improvement in ARAT scores is $12.42 \%$. The mean difference in pre- and post-intervention FMA scores was $8.38 \pm 2.14$ ( $\mathrm{p}<0.01$ ). The percentage-wise improvement in FMA scores is $12.70 \%$. The mean difference in pre- and post-intervention VCG scores was $1.15 \pm 0.69(\mathrm{p}<0.01)$. The percentage-wise improvement in VCG scores is $19.33 \%$. These results show that there is statistically significant improvement in all outcome measures seen in Group $\mathrm{C}$ on intra-group comparison.

Also on inter-group comparison, Group C was much ahead than other 2 groups, while group B lagged in terms of all outcome measures. Group C improved 1.60 times more than group A and 3.21 times more than group B in terms of ARAT. Group C improved 1.55 times more than group A and 2.39 times more than group B in terms of FMA. Group C improved 1.98 times more than group A and 3.48 times more than group B in terms of VCG.

These results in group $\mathrm{C}$ could be because of combined working mechanisms of TSE and MT as stated above. Repeated meaningful activities by affected UL as in TSE component might have helped to induce cortical reorganization while mirror illusion of unaffected UL might have substituted for the decreased proprioceptive feedback. Also there is possibility of activation of mirror neuron system. Also it has been mentioned in the literature that priming effects of motor imagery (MI) on subsequent physical performance observed in healthy individuals are in line with the notion that MI has a preparatory effect and enhances the efficacy of subsequent physical training [57-59]. Stevens and Stoykov [33] suggested that MT is related to motor imagery as the mirror creates visual feedback of successful performance of the imagined action with the impaired limb. So the gains found in the combined group could also be reflecting priming effects of MT induced MI on physical execution with TSE [57, 59]. 


\section{Conclusion}

This present study provides promising results on the added value of combining mirror therapy along with Task specific exercises of the same task within the same training session for improving upper limb function in subacute stroke patients. So on the basis of the present study, it can be concluded that mirror therapy can be added along with task specific exercises in the treatment of sub-acute stroke patients to improve upper limb function.

Limitations of the present study: This study did not stratified on the level of arm deficit and did not have true control group. Also, sample size was small which included participants from a single geographic location.

Suggestions for further research: Future study should include long term intervention period. Follow up assessment should be done to know the retention effect of these interventions. Also future studies should try to identify patients who might profit more by MT than others, to guide more specific intervention through MT. Since MT is a relatively new intervention hence, the assessment of potential risks of a new intervention is mandatory in patient-reported outcomes to decide on the clinical utility of a treatment. Future studies must systematically register adverse effects.

Funding: No funding support was received from any source.

Conflict of interest: None declared.

\section{References}

[1] Kimberlee, J, Marcus K. Augmented Reality Assisted Upper Limb Rehabilitation Following Stroke. 2012.

[2] Kwakkel G, Kollen BJ, van der Grond, J, Prevo AJ. Probability of Regaining Dexterity in the Flaccid Upper Limb Impact of Severity of Paresis and Time Since Onset in Acute Stroke. Stroke 2003; 34 (9):2181-2186.

[3] Dean CM, Richards CL, Malouin F. Task-related circuit training improves performance of locomotor tasks in chronic stroke: a randomized, controlled pilot trial. Archives of physical medicine and rehabilitation 2000; 81(4):409-417.

[4] Dunning K, Berberich A, Albers B, Mortellite K, Levine PG, Page SJ. A four-week, task-specific neuroprosthesis program for a person with no active wrist or finger movement because of chronic stroke. Physical therapy 2008; 88(3):397-405.

[5] Blennerhassett J \& Dite W. Additional task-related practice improves mobility and upper limb function early after stroke: a randomised controlled trial. Aust J Physiother 2004; 50(4):219-224.

[6] Newman M. The Process of Recovery: After Hemiplegia. Stroke 1971; 3(6): 702-710.

[7] Teasell RW, Foley NC, Salter KL, Jutai JW. A Blueprint For Transforming Stroke Rehabilitation Care In Canada: The Case For Change. Archives of Physical Medicine and Rehabilitation 2008; 89:575-578.

[8] Schmidt RA, Lee TD. Motor Control and Learning: A Behavioural Emphasis, 4th edition. Champaign IL: Human Kinetics. 2005.

[9] Winstein CJ, Campbell SJ. Conditions of task practice for individuals with neurologic impairments. In: Textbook of Neural Repair and Rehabilitation: Volume II Medical Neurorehabilitation. Cambridge University Press; 2006.

[10] Hubbard IJ, Parsons MW, Neilson C, Carey LM. Task-specific training: evidence for and translation to clinical practice. Occupational Therapy International 2009; 16(3-4): 175-189.

[11] Shumway-Cook A, Woollacott MH. Motor Control: Translating Research Into Clinical Practice. Lippincott Williams \& Wilkins; 2006.

[12] French B, Leathley M, Sutton C, McAdam J, Thomas L, Forster A, et al. A Systematic Review Of Repetitive Functional Task Practice With Modelling Of Resource Use, Costs And Effectiveness. Health Technology Assessment 2008; 12:1-117.

[13] Carr J, Shepherd R. A motor relearning programme for stroke. 1982.

[14] Bayona NA, Bitensky J, Salter K, Teasell R. (2005). The role of task-specific training in rehabilitation therapies. Topics in Stroke Rehabilitation 2005; 12(3): 58

[15] Byl N, Roderick J, Mohamed O, Hanny M, Kotler J, Smith A, et al. Effectiveness of Sensory and Motor Rehabilitation of The Upper Limb Following The Principles of Neuroplasticity: Patients Stable Poststroke. Neurorehabilitation And Neural Repair 2003; 17(3):176-191.

[16] Mathiowetz V. Task-oriented approach to stroke rehabilitation. Stroke rehabilitation: A function-based approach. St. Louis, MO: Mosby, 59-74. In: Gillen G, Burkhardt A (eds). Stroke Rehabilitation: A Function-based Approach. 2nd edition: 59-74. Mosby Elsevier; 2004.

[17] Dobkin BH, Carmichael S. Principles of recovery after stroke. Cambridge University Press, Cambridge; 2005.

[18] Carey LM. Loss of somatic sensation. Textbook of neural repair and rehabilitation 2006; 2:231-247.

[19] Davis JZ. Task selection and enriched environments: a functional upper extremity training program for stroke survivors. Topics in stroke rehabilitation 2006; 13(3): 1-11.

[20] Krakauer JW. Motor learning: its relevance to stroke recovery and neurorehabilitation. Current opinion in neurology 2006; 19(1): 84-90.

[21] Richards LG, Stewart KC, Woodbury ML, Senesac C, Cauraugh JH. Movement-dependent stroke recovery: a systematic review and meta-analysis of TMS and fMRI evidence. Neuropsychologia 2008; 46(1):3.

[22] Karni A, Meyer G, Jezzard P, Adams M, Turner R, Ungerleider L. Functional MRI evidence for adult motor cortex plasticity during motor skill learning. Nature 1995; 377: 155-158.

[23] Plautz EJ, Milliken GW, Nudo RJ. Effects of repetitive motor training on movement representations in adult squirrel monkeys: role of use versus learning. Neurobiology of learning and memory 2000; 74(1); 27-55.

[24] Goldstone RL. Perceptual learning. Annual review of psychology 1998; 49(1): 585-612.

[25] Ezendam D, Bongers RM, Jannink MJ. Systematic review of the effectiveness of mirror therapy in upper extremity function. Disability \& Rehabilitation 2009; 31(26): 2135-2149.

[26] Ramachandran VS. Phantom limb, neglect syndromes, repressed memories and Freudian psychology. Int Rev Neurobiol 1994; $37: 291-333$ 
[27] Rothgangel AS, Braun SM, Beurskens AJ, Seitz RJ, Wade DT. The clinical aspects of mirror therapy in rehabilitation: a systematic review of the literature. International Journal of Rehabilitation Research 2011;34(1):1.

[28] Higgins J, Salbach NM., Wood-Dauphinee S, Richards CL, Côté R, Mayo NE. The effect of a task-oriented intervention on arm function in people with stroke: a randomized controlled trial. Clinical rehabilitation 2006; 20(4):296-310.

[29] Birkenmeier RL, Prager EM, Lang CE. Translating animal doses of task-specific training to people with chronic stroke in 1-hour therapy sessions: a proof-of-concept study. Neurorehabilitation and neural repair 2010; 24(7):620-635.

[30] Dohle C, Püllen J, Nakaten A, Küst J, Rietz C, Karbe H. Mirror therapy promotes recovery from severe hemiparesis: a randomized controlled trial. Neurorehabilitation and neural repair 2009; 23(3):209-217.

[31] Kwakkel G, Wagenaar R, Twisk J, Lankhorst G, Koetsier J. Intensity of leg and arm training after primary middle-cerebral-artery stroke. The Lancet 1999; 354(9174):191-196.

[32] Carr J, Shepherd R. Movement Science: Foundations for Physical Therapy in Rehabilitation. 2nd edition: Aspen Publishers; 2000.

[33] Stevens JA, Stoykov MEP. Using motor imagery in the rehabilitation of hemiparesis. Archives of physical medicine and rehabilitation 2003; 84(7):1090-1092.

[34] Nudo RJ, Milliken GW. Reorganization of movement representations in primary motor cortex following focal ischemic infarcts in adult squirrel monkeys. Journal of Neurophysiology 1996; 75:2144-2149.

[35] Calautti C, Leroy F, Guincestre JY, Marie RM, Baron JC. Sequential activation brain mapping after subcortical stroke: changes in hemispheric balance and recovery. Neuroreport 2001; 12:3883-3886.

[36] Carey LM, Seitz RJ. Functional neuroimaging in stroke recovery and neurorehabilitation: conceptual issues and perspectives. International Journal of Stroke 2007; 2:245-264.

[37] Jang SH, Kim YH, Cho SH, Lee JH, Park JW, Kwon YH. Cortical reorganization induced by task-oriented training in chronic hemiplegic stroke patients. Neuroreport 2003; 14(1):137-141.

[38] Classen J, Liepert J, Wise SP, Hallett M, Cohen LG. Rapid plasticity of human cortical movement representation induced by practice. J Neurophysiol 1998; 79(2):1117-1123.

[39] Kilgard MP, Merzenich MM. Cortical map reorganization enabled by nucleus basalis activity. Science 1998; 279(5357):1714-1718.

[40] Page SJ. Intensity versus task-specificity after stroke: how important is intensity? American Journal of Physical Medicine \& Rehabilitation 2003; 82: 730-732.

[41] Duncan PW, Badke MB. Stroke Rehabilitation. The Recovery of Motor Function. Chicago: Year Book; 1987.

[42] Winstein CJ, Rose DK, Tan SM, Lewthwaite R, Chui HC, Azen SP. A randomized controlled comparison of upper-extremity rehabilitation strategies in acute stroke: a pilot study of immediate and long-term outcomes. Archives of physical medicine and rehabilitation 2004; 85(4):620-628.

[43] Dean CM, Shepherd RB. Task-Related Training Improves Performance of Seated Reaching Tasks After Stroke A Randomized Controlled Trial. Stroke 1997; 28(4):722-728.

[44] Ramachandran VS, Altschuler EL. The use of visual feedback, in particular mirror visual feedback, in restoring brain function. Brain 2009; 132(7):1693-1710.

[45] Sterr A, Freivogel S, Schmalohr D. Neurobehavioral aspects of recovery: assessment of the learned nonuse phenomenon in hemiparetic adolescents. Archives of Physical Medicine And Rehabilitation 2002; 83(12): 1726-1731.

[46] Van Dijk H, Jannink MJA, Hermens HJ. Effect of augmented feedback on motor function of the affected upper extremity in rehabilitation patients: a systematic review of randomized controlled trials. J Rehabil Med 2005; 37: 202-211.

[47] Moseley GL. Graded motor imagery for pathologic pain: A randomized controlled trial. Neurology 2006; 67(12):2129-2134.

[48] Franceschini M, Agosti M, Cantagallo A, Sale P, Mancuso M, Buccino G. Mirror neurons: action observation treatment as a tool in stroke rehabilitation. European journal of physical and rehabilitation medicine 2010; 46 (4): 517.

[49] Dushanova J, Donoghue J: Neurons in Primary Motor Cortex Engaged During Action Observation. Eur J Neurosci 2010; 31 (2):386398.

[50] James M. Kilner. More than one pathway to action understanding. Trends Cogn Sci. 2011; 15(8):352-357.

[51] Iacoboni M, Mazziotta JC. Mirror Neuron System: Basic Findings and Clinical Applications. Ann Neurol 2007; 62:213-218.

[52] Gallese V, Fadiga L, Fogassi L, Rizzolatti G. Action recognition in the premotor cortex. Brain 1996; 119(2):593-609.

[53] Filimon F, Nelson JD, Hagler DJ, Sereno MI. Human cortical representations for reaching: mirror neurons for execution, observation, and imagery. Neuroimage 2007; 37:1315-132.

[54] Garry MI, Loftus A, Summers JJ. Mirror, mirror on the wall: viewing a mirror reflection of unilateral hand movements facilitates ipsilateral M1 excitability. Experimental brain research 2005; 163(1):118-122.

[55] Michielsen ME. Motor recovery and cortical reorganization after mirror therapy in chronic stroke patients - conducted a phase II randomized controlled trial. Neurorehabil Neural Repair 2011; 25(3):223-33.

[56] Yavuzer G, Selles R, Sezer N, Sutbeyaz S, Bussmann JB, Koseoglu F, et al. Mirror therapy improves hand function in subacute stroke: a randomized controlled trial. Archives of physical medicine and rehabilitation 2008; 89(3):393-398.

[57] Allami N, Paulignan Y, Brovelli A. Visuo-motor learning with combination of different rates of motor imagery and physical practice. Exp Brain Res. 2008; 184:105-113.

[58] Pascual-Leone A, Nguyet D, Cohen LG, et al. Modulation of muscle responses evoked by transcranial magnetic stimulation during the acquisition of new fine motor skills. J Neurophysiol 1995; 74: 1037-1045.

[59] Jackson PL, Lafleur MF, Malouin F. Functional cerebral reorganization following motor sequence learning through mental practice with motor imagery. Neuroimage 2003; 20: 1171-1180. 